\title{
A short note on the Erdös-Debrunner inequality
}

\author{
Walther Janous* \\ Walther Janous hat an der Universität in Innsbruck und an der Ohio State University \\ in Columbus (USA) studiert. Seit 1978 arbeitet er als Gymnasialprofessor an einer \\ Mädchenschule in Innsbruck. Neben seiner Lehrtätigkeit ist er auch im Betreuerteam \\ der österreichischen Mathematikolympiade engagiert und mitverantwortlich für die \\ „Wissenschaftlichen Nachrichten“, einem für österreichische Gymnasiallehrer heraus- \\ gegebenen Organ.
}

\section{Introduction}

Let $A B C$ be an arbitrary triangle and $D, E, F$ arbitrary points on sides $B C, C A, A B$, resp., all three being different from the vertices of $A B C$.

Then, triangle $A B C$ is divided into four smaller triangles, a central one $D E F$, and three corner ones $A E F, B D F, C E D$.

* This research is partially supported by grant 04-39-3265-2/03 (11.XII.2003) of the Federal Ministery of Education and Sciences, Bosnia and Herzegowina.

Ungleichungen, die verschiedene Elemente eines oder mehrerer Dreiecke in Beziehung zueinander setzen, haben in der mathematischen Literatur eine lange Tradition. Wegen ihrer Schönheit und den oft überraschenden Ideen dahinter treten sie häufig in den Aufgabenteilen vieler Zeitschriften und mitunter auch bei mathematischen Wettbewerben auf. Ein Beispiel eines derartigen Ergebnisses ist die in diesem Beitrag betrachtete auf P. Erdös und H. Debrunner zurückgehende Ungleichung, in der die Flächeninhalte von vier Teildreiecken eines beliebigen Ausgangsdreiecks verglichen werden. Im vorliegenden Beitrag wird der beste Exponent einer analogen Ungleichung, in der das Potenzmittel von drei der vier Flächeninhalte durch den vierten abgeschätzt wird, auf ein kleines Intervall eingegrenzt. Für den genauen Wert dieses Exponenten wird eine Vermutung aufgestellt. 


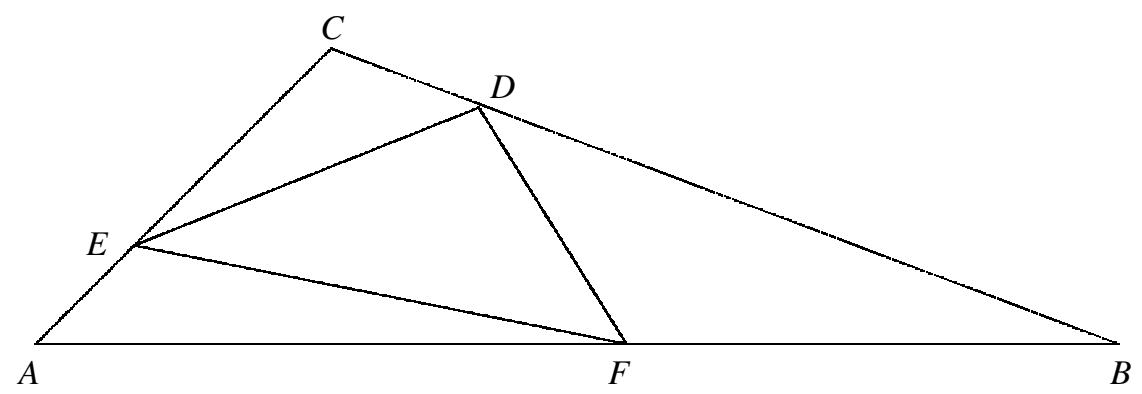

Let $F_{1}, F_{2}, F_{3}$ be the areas of the three corner triangles and $F_{0}$ be the one of the central triangle. Then the Erdös-Debrunner inequality says

$$
F_{0} \geq \min \left(F_{1}, F_{2}, F_{3}\right),
$$

where equality occurs if and only if $D, E, F$ are the midpoints of the respective sides. See [1, p. 81] for an extensive list of references concerning this inequality; furthermore, the appropriate chapters in [3] and [4] report a host of results (and some of their proofs) related to two triangles, one inscribed in the other.

Speaking in the language of power-means, inequality (1) reads

$$
F_{0} \geq M_{-\infty}\left(F_{1}, F_{2}, F_{3}\right),
$$

where the $p$-th power-mean of three positive real numbers $x, y, z$ is defined by

$$
M_{p}(x, y, z)= \begin{cases}\left(\frac{x^{p}+y^{p}+z^{p}}{3}\right)^{(1 / p)} & p \neq 0, \\ \sqrt[3]{x y z} & p=0 .\end{cases}
$$

Then, $M_{p}(x, y, z)$ is (weakly) increasing as $p$ increases, and

$$
M_{-\infty}(x, y, z)=\lim _{p \rightarrow-\infty} M_{p}(x, y, z)=\min (x, y, z) .
$$

Therefore, it is natural to ask whether or not there do exist inequalities of the type

$$
F_{0} \geq M_{p}\left(F_{1}, F_{2}, F_{3}\right),
$$

where $p>-\infty$.

Subsequently, we will show that this is indeed so and we will give a bound for the maximum value $p_{\max }$ of $p$. Thereby, we will also falsify a result stated and "proven" in [2]. At the end of this note, we shall state two conjectures for further research.

\section{Bounds for $p_{\max }$}

Before stating the announced result, we are going to introduce the method of proof frequently applied in situations as the present one. 
Let $B C, C A, A B$ be divided by $D, E, F$ in ratios $t:(1-t), u:(1-u), v:(1-v)$, resp., where $0<t, u, v<1$. Then, we have

$$
F_{1}=(1-u) \cdot v \cdot F_{\triangle}, \quad F_{2}=(1-v) \cdot t \cdot F_{\triangle}, \quad F_{3}=(1-t) \cdot u \cdot F_{\triangle},
$$

where $F_{\triangle}$ denotes the area of triangle $A B C$. For this, note for instance for $F_{1}: A F=$ $v \cdot A B$, and $A E=(1-u) \cdot A C$. Therefore, $F_{0}=F_{\triangle}-F_{1}-F_{2}-F_{3}$ becomes

$$
F_{0}=(t \cdot u \cdot v+(1-t) \cdot(1-u) \cdot(1-v)) \cdot F_{\triangle}
$$

Furthermore,

$$
\frac{F_{0}}{F_{1}}=\frac{1-t-u-v+t u+t v+u v}{(1-u) v}=\frac{1-t}{v}+\frac{t}{1-u}-1
$$

Since we get similar expressions for $F_{0} / F_{2}$ and $F_{0} / F_{3}$, we introduce the notation

$$
x=\frac{t}{1-u}, \quad y=\frac{u}{1-v}, \quad z=\frac{v}{1-t},
$$

yielding

$$
\frac{F_{0}}{F_{1}}=\frac{1}{z}+x-1, \quad \frac{F_{0}}{F_{2}}=\frac{1}{x}+y-1, \quad \frac{F_{0}}{F_{3}}=\frac{1}{y}+z-1 .
$$

We now show that $p$ has to be negative for inequality (2) to hold in general. Indeed, let $p=0$. Then, for (2) the inequality $F_{0} / F_{1} \cdot F_{0} / F_{2} \cdot F_{0} / F_{3} \geq 1$ had to be valid. But $t=1 / 2$, $u=1 / 3$ and $v=2 / 3$ lead to the contradiction $8 / 9 \geq 1$.

Therefore, we let $p=-q$, where $q>0$, and thus, obtain for (2) the equivalent inequality

$$
F_{1}^{-q}+F_{2}^{-q}+F_{3}^{-q} \geq 3 \cdot F_{0}^{-q}
$$

i.e.,

$$
\left(\frac{F_{0}}{F_{1}}\right)^{q}+\left(\frac{F_{0}}{F_{2}}\right)^{q}+\left(\frac{F_{0}}{F_{3}}\right)^{q} \geq 3,
$$

hence,

$$
\left(\frac{1}{z}+x-1\right)^{q}+\left(\frac{1}{x}+y-1\right)^{q}+\left(\frac{1}{y}+z-1\right)^{q} \geq 3,
$$

where of course $x, y, z>0$ have to satisfy

$$
\frac{1}{z}+x-1 \geq 0, \quad \frac{1}{x}+y-1 \geq 0, \quad \frac{1}{y}+z-1 \geq 0 .
$$

We are now in the position to state and prove the following

Theorem. The quantity $p_{\max }$ in inequality (2) satisfies

$$
-1 \leq p_{\max } \leq-\frac{\ln (3 / 2)}{\ln (2)}
$$


Proof. In order to prove this assertion, we have to show that the minimal value $q_{\min }$ such that inequality (3) holds true in general, fulfils $\ln (3 / 2) / \ln (2) \leq q_{\min } \leq 1$.

i) Case $q_{\text {min }} \leq 1$ : Indeed, inequality (3) becomes for $q=1$

$$
x+\frac{1}{x}+y+\frac{1}{y}+z+\frac{1}{z} \geq 6 .
$$

But this inequality follows from $t+1 / t \geq 2$, whenever $t>0$.

ii) Case $q_{\min } \geq \ln (3 / 2) / \ln (2)$ : We let $t=1 / 2$, and $v=1-u(0<u<1)$. Then, we find

$$
\frac{F_{0}}{F_{1}}=\frac{u}{1-u}, \quad \frac{F_{0}}{F_{2}}=\frac{F_{0}}{F_{3}}=2(1-u),
$$

whence inequality (3) reads

$$
\left(\frac{u}{1-u}\right)^{q}+2 \cdot(2(1-u))^{q} \geq 3
$$

with $0<u<1$. Since the expression on the left-hand side of this inequality is continuous as $u \rightarrow 0$, we arrive at $2 \cdot 2^{q} \geq 3$, which completes the proof of the theorem.

Remark. In [2] it is "shown" by an erroneous argument that $p_{\max }$ equals $-1 / 3$ contradicting the inequality $p_{\max } \leq-\ln (3 / 2) / \ln (2)=-0.58 \ldots$

\section{Two conjectures}

At the end of this note we state two conjectures. (The second of them is very likely to be settled by non elementary means only.)

Conjecture 1. Let $x, y$ and $z$ be positive real numbers such that $1 / z+x-1 \geq 0$, $1 / x+y-1 \geq 0$ and $1 / y+z-1 \geq 0$. Then, for any $q>0$ the minimum of the left-hand expression in (3) is attained at $x, y$ and $z$ satisfying $x \cdot y \cdot z=1$.

Conjecture 2. In the above theorem, the equality $p_{\max }=-\ln (3 / 2) / \ln (2)$ holds true.

\section{References}

[1] Bottema, O. et al.: Geometric Inequalities. Wolters and Noordhoff, Groningen 1969.

[2] Mavlo, D.: Solution of Problem 4 (posed by himself) [in Bulgarian]. Obuch. po matem. i inform. XIV (1989) 3, 48-51.

[3] Mitrinović, D.S. et al.: Recent Advances in Geometric Inequalities. Kluwer Acad. Publ., Dordrecht 1989.

[4] Mitrinović, D.S. et al.: Addenda to the Monograph Recent Advances in Geometric Inequalities. I. J. Ningbo Univ. 4 (1991) 2, 79-145.

Walther Janous

Ursulinengymnasium

Fürstenweg 86

A-6020 Innsbruck, Austria

e-mail: walther.janous@tirol.com 